\title{
Reactivity of Blueberry Leaf Polyphenols with Formaldehyde
}

\author{
Yingchang $\mathrm{Li}^{1,2, a}$, Zhongyan Yang ${ }^{1,2, b}$ and Jiangrong $\mathrm{Li}^{1,2, \mathrm{c}}$ \\ ${ }^{1}$ College of Food Science and Technology, Bohai University, Jinzhou 121013, China; \\ ${ }^{2}$ National \& Local Joint Engineering Research Center \\ of Storage, Processing and Safety Control Technology for Fresh Agricultural and Aquatic Products; \\ Jinzhou 121013, China \\ aliyingchangsy@sina.com \\ byang110rui@163.com \\ clijr6491@163.com
}

\begin{abstract}
Keywords: Blueberry leaf polyphenols, Formaldehyde, Reactivity
Abstract. Formaldehyde exists in aquatic products, Lentinula edodes and other foods. For better application of blueberry leaf polyphenols as formaldehyde capture agent, the reaction conditions of blueberry leaf polyphenols with formaldehyde were studied under different polyphenols concentration, $\mathrm{pH}$ value, reaction temperature and reaction time. The effects of the $\mathrm{pH}$, reaction temperature and reaction time on the reduction rate of formaldehyde were optimized by a response surface methodology (RSM). The results showed that $\mathrm{pH}$ most significantly affected on reactivity of blueberry leaf polyphenols with formaldehyde, followed by temperature and reaction time. The optimal polyphenols concentration was $0.2 \%$. The reactivity was the lowest at $\mathrm{pH} 3.0-4.0$ and higher at strong acidic and alkaline conditions. Prolonging time facilitated the reaction under the higher temperature. There is a great prospect with blueberry leaf polyphenols as formaldehyde capture agent for aquatic products and other foods.
\end{abstract}

\section{Introduction}

Formaldehyde (FA) is both an industrial product and an essential metabolite of aquatic products and vegetables. It was found that more than $90 \%$ trimethylamine oxide (TMAO) was converted to TMA and DMA after heat treatment of dried squid for $1 \mathrm{~h}$ at $200{ }^{\circ} \mathrm{C}$ [1]. TMAO in some aquatic products can be degraded to formaldehyde and dimethylamine by at least two pathways. Firstly, Formaldehyde is produced enzymatic decomposition of trimethylamine-oxide (TMAO) to equimolar amounts of formaldehyde and dimethylamine (DMA) in seafood and crustaceans during storage. Secondly, Formaldehyde is also produced via the degradation of TMAO during thermal processing. Formaldehyde (FA) is a reactive substance that has the ability of reacting with many functional groups of proteins, especially free amino groups, which contributes to denature proteins and damage quality of aquatic products. Tong et al. showed that the formaldehyde interferes with DNA methyltransferase function, causing memory loss in Alzheimer's disease [2]. Formaldehyde has been identified carcinogens by World Health Organization, can cause a variety of cancers, especially leukemia [3]. Some studies showed that formaldehyde can injury arterial endothelial cell and cause arteriosclerosis [4]. Formaldehyde can also cause abnormalities of pulmonary, liver, immune system and injury nervous system [5].

Recently, much attention has been paid to formaldehyde (FA) in aquatic products, taking into account the potential adverse effects on human health related to seafood consumption. We should take effective measures to control the formaldehyde in aquatic products. Sodium pyrophosphate and sodium citrate were proved the high inhibitory effect on TMAOase activity from lizardfish muscle [6]. Green tea catechins were found to have reactivity with formaldehyde, and galloyl group effectively enhanced reactivity with formaldehyde [7]. Blueberry leaf can be used in medicine and food. Tea polyphenols can reduce formaldehyde content in aquatic products because it can react with formaldehyde [8]. Blueberry leaf polyphenol is a kind of important functional components in blueberry leaves. Polyphenol compounds from blueberry leaves were different compared with tea polyphenols. It is worthy of discussion whether blueberry leaf polyphenols can react with 
formaldehyde. In this work, we examined the effects of polyphenols concentration, $\mathrm{pH}$, temperature and reaction time on reactivity of polyphenols with formaldehyde. It provided certain ideas of blueberry leaf polyphenols as capture agent for formaldehyde.

\section{Materials and methods}

\section{Chemical reagents}

The standard formaldehyde solution was purchased from Standard Sample Research Institution of State Environmental Protection Administration, Beijing, China. Methanol (chromatographic grade) was purchased from DIKMA Company. Formaldehyde, ethanol and sodium hydroxide were analytical grade and obtained from Tianjing Zhiyuan Chemical Reagent Co. Lid. (Tianjin, China). AB-8 macroporous resin was provided by Cangzhou the Bao En adsorption material Technology Co., Ltd., Hebei, China.

\section{Preparation of blueberry leaf polyphenols}

The blueberry leaves were obtained from bushes of Vaccinium bracteatum Thunb at the blueberry planting base of Shenyang Academy for Development of Agricultural Science and Technology, Liaoning Province, China. The blueberry leaves were dried at $50{ }^{\circ} \mathrm{C}$, crushed by a grinder and sieved by a 40-mesh sieve. Briefly, $100 \mathrm{~g}$ dry coarse powder of blueberry leaves was extracted in $2 \mathrm{~L}$ of $70 \%$ (v/v) ethanol at $60{ }^{\circ} \mathrm{C}$ for $120 \mathrm{~min}$. Total blueberry leaf polyphenols were filtered twice through filter paper, concentrated using a rotary evaporator at $50{ }^{\circ} \mathrm{C}$ and defatted with petroleum ether. The extract was loaded on a column with AB-8 macroporous resin for adsorption for $12 \mathrm{~h}$. The column was then washed with water to get rid of impurities. Polyphenols extract in the column was eluted with $70 \%$ (v/v) ethanol. The eluate was condensed by a rotary evaporator at $50{ }^{\circ} \mathrm{C}$ and then further dried to yellow powder using a freeze-dryer at $-50{ }^{\circ} \mathrm{C}$.

\section{Determination of blueberry leaf polyphenols content}

The polyphenols content was determined using the Folin-Ciocalteu method, described by Singleton et al, with slightly modifications [9]. Using garlic acid as the standard, the regression equation between garlic acid concentration $(\mu \mathrm{g} / \mathrm{mL})$ and absorbance value was obtained as $\mathrm{y}=0.1037 \mathrm{x}+0.0109\left(\mathrm{R}^{2}=0.9992\right)$, where, $\mathrm{y}$ was the absorbance at $750 \mathrm{~nm}$, $\mathrm{x}$ was garlic acid concentration $(\mu \mathrm{g} / \mathrm{mL})$. The absorbance of blueberry leaf polyphenols extract was also determined at $750 \mathrm{~nm}$. Polyphenols concentration was calculated according to the regression equation described above, then polyphenols content was calculated as follows: Polyphenols content $(\%)=\mathrm{C} \times \mathrm{V} \times 100 /(\mathrm{m} \times 1000)$, Where $\mathrm{C}$ was concentration of polyphenols $(\mu \mathrm{g} / \mathrm{mL}), \mathrm{V}$ was volume of sample $(\mathrm{mL})$ and $\mathrm{m}$ was weight of polyphenols extract $(\mathrm{g})$, respectively. The apparent polyphenols content of the extract was determined quantitatively as $78.06 \%$.

\section{Determination formaldehyde by HPLC}

The formaldehyde content was determined by HPLC method, described by Li et al., with slightly modifications [10]. The high-performance liquid chromatography (HPLC) system was Agilent 1200 HPLC instrument (Agilent Technologies, USA). The HPLC column was an Eclipse Plus ODS-C 18 $(5 \mu \mathrm{m}, 250 \mathrm{~mm} \times 4.6 \mathrm{~mm})$. The sample volume was $20 \mathrm{uL}$ and the absorb wavelength of UV detector was $355 \mathrm{~nm}$. The mobile phase was methanol-water $(60: 40, \mathrm{v} / \mathrm{v})$ with a flow rate of $1 \mathrm{~mL} / \mathrm{min}$. The peak area was used for quantitative calculation of formaldehyde. $0.00,0.40,0.80,1.20,1.60$ and 2.00 $\mathrm{mL}$ formaldehyde solution from $10 \mu \mathrm{g} / \mathrm{mL}$ stock formaldehyde solution, were transferred into flask, respectively, and added to high-purity water to $4 \mathrm{~mL}$. Then, $2 \mathrm{~mL}$ 2,4-dinitrophenyl hydrazine was added to flask and was heated in water bath at $60{ }^{\circ} \mathrm{C}$ for $30 \mathrm{~min}$. The samples were left to cool at room temperature and filtered using $0.45 \mu \mathrm{m}$ membranes. Analyses were performed by high performance liquid chromatography at $355 \mathrm{~nm}$. Three injections of each standard solution were made and the peak area represented the corresponding formaldehyde concentration.

\section{Single-factor-test of reactivity polyphenols with formaldehyde}

The effect of different concentration of polyphenols, $\mathrm{pH}$, temperature and reaction time on the reactivity of polyphenols with formaldehyde was examined. Reduction rate of formaldehyde (\%) was calculated as follows: 
Reduction rate of formaldehyde $(\%)=(A-B) / A \times 100$, where, $A$ was content of formaldehyde before reacting, $\mu \mathrm{g} / \mathrm{mL}$, B was content of formaldehyde after reacting, $\mu \mathrm{g} / \mathrm{mL}$, respectively.

\section{Optimization of the reaction conditions of polyphenols with formaldehyde}

Response surface methodology (RSM) was used to determine the optimum reaction conditions for polyphenols with formaldehyde. The experimental design and statistical analysis was done by Stat-Ease software. A three-factor of three-level Box-Behnken design (BBD) was chosen to evaluate the combined effect of three independent variables, $\mathrm{pH}\left(\mathrm{X}_{1}\right)$, temperature $\left({ }^{\circ} \mathrm{C}, \mathrm{X}_{2}\right)$ and time (min, $\mathrm{X}_{3}$ ). The minimum and maximum values of $\mathrm{pH}$ were 6.0 and 8.0 , of temperature were $80{ }^{\circ} \mathrm{C}$ and 100 ${ }^{\circ} \mathrm{C}$, of time were 30 and 90 min, respectively.

\section{Statistical analysis}

All experiments were carried out in triplicate and all the data were expressed as mean \pm standard deviation (SD) (n=3). Data was subjected to analysis of variance using SAS Version 6.12 (SAS Institute, Cary, NC, USA). $P<0.05$ was a significant difference.

\section{Results and Discussions}

\section{Effect of polyphenols concentration on reactivity of polyphenols with formaldehyde}

As shown in Fig.1, reduction rate of formaldehyde increased as ployphenols concentration increased. Reduction rate of formaldehyde significantly increased $(P<0.05)$ was observed from 0.05 $\%$ to $0.20 \%$ of polyphenols concentration and reduction rate of formaldehyde was $4.54 \%$ and 10.93 $\%$, respectively. The reason was that the number of activated polyphenols molecules increased with the increase of polyphenols concentration. The reaction activity of polyphenols with formaldehyde was also concerned with the structure and composition of polyphenols. Reduction rate of formaldehyde increased at a lower rate when polyphenos concentration was over $0.20 \%$. Reduction rate had no remarkable differences $(P>0.05)$ among $0.2 \%, 0.25 \%$ and 0.30 of polyphenols concent. Considering the actual processing, $0.20 \%$ blueberry leaf polyphenols was selected.

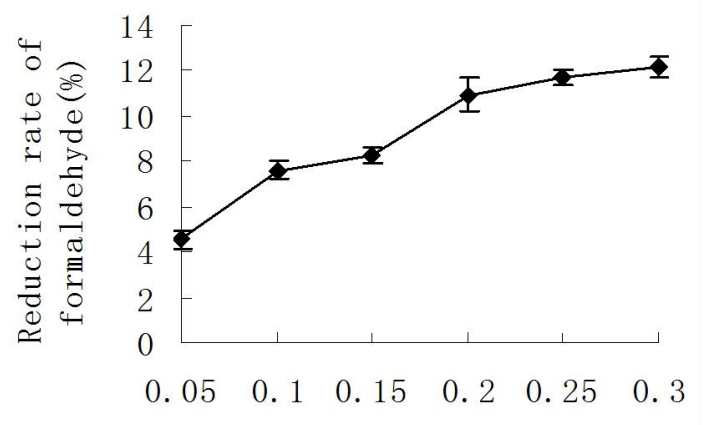

Polyphenols concentration(\%)

Fig.1 Effect of concentration on reaction of blueberry leaf polyphenols with formaldehyde

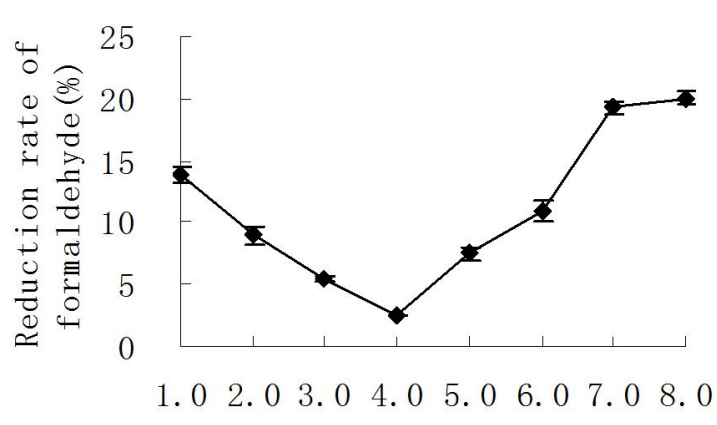

$\mathrm{pH}$ value

Fig.2 Effect of $\mathrm{pH}$ on reaction of blueberry leaf polyphenols with formaldehyde

Effect of pH on reactivity of polyphenols with formaldehyde

As shown in Fig.2, reduction rate of formaldehyde significantly decreased $(P<0.05)$ as $\mathrm{pH}$ increased at $\mathrm{pH} 1.0-4.0$. Reduction rate of formaldehyde was the lowest at $\mathrm{pH} 4.0$. Reduction rate of formaldehyde significantly increased $(P<0.05)$ as $\mathrm{pH}$ increased at $\mathrm{pH} 4.0-8.0$. It showed that the reaction of polyphenols with formaldehyde was catalyzed by acid or alkali. The reactivity of polyphenols with formaldehyde increased and formaldehyde content decreased when $\mathrm{pH}$ was increased or decreased except $\mathrm{pH} 3.0$ to 4.0. The reactivity of ployphenols with formaldehyde was higher at $\mathrm{pH} 7.0$ and $\mathrm{pH} 8.0$ than that of other $\mathrm{pH}$. The effect of $\mathrm{pH}$ on the reaction of polyphenols with formaldehyde was significant. We should select the higher $\mathrm{pH}$ in practical application.

\section{Effect of temperature on reactivity of polyphenols with formaldehyde}

As shown in Fig.3, Reduction rate of formaldehyde significantly increased $(P<0.05)$ with the elevation of temperature. Reduction rate of formaldehyde was only $3.73 \%$ at $4{ }^{\circ} \mathrm{C}$, while reduction 
rate of formaldehyde reached $30.37 \%$ at $100{ }^{\circ} \mathrm{C}$. Reduction rate of formaldehyde increased because the number of active molecules of polyphenols and formaldehyde increased due to high temperature. Zhu et al. reported that formaldehyde levels was significantly increased in the supernatant of jumbo squid with the increase of heating temperature[11].In our work found that the higher temperature was beneficial to the reaction of polyphenols with formaldehyde, so blueberry leaf polyphenols can also capture more formaldehyde in the squids at high temperature, and decreased formaldehyde content in the squids. In practical application, we should select high temperature in the proper range.

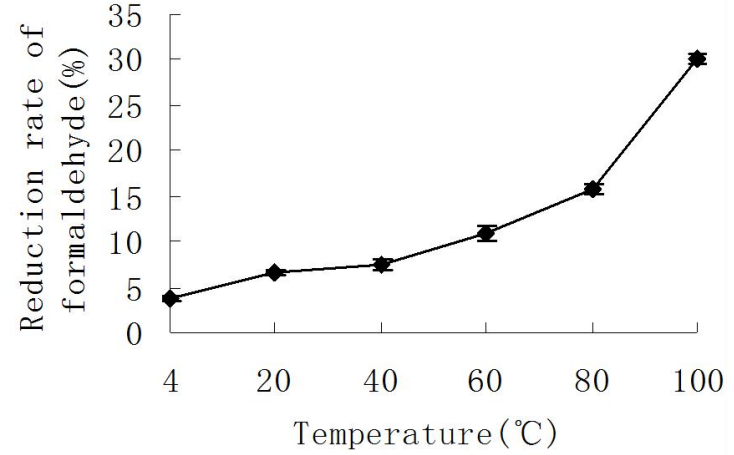

Fig.3 Effect of temperature on reaction of blueberry leaf polyphenols with formaldehyde

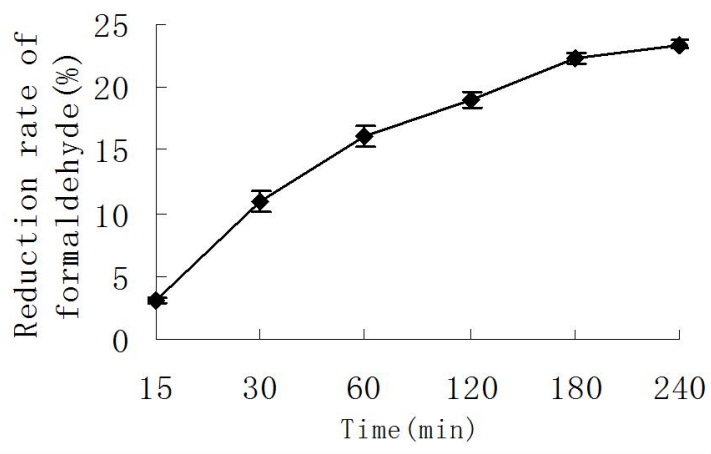

Fig.4 Effect of time on reaction of blueberry leaf polyphenols with formaldehyde

Effect of reaction time on reactivity of polyphenols with formaldehyde

As shown in Fig.4, reduction rate of formaldehyde significantly increased $(P<0.05)$ with time extending. Reduction rate of formaldehyde rapidly increased in firstly $60 \mathrm{~min}$, and then slowly increased, which was related to polyphenols content reduced with reaction time extending. Reduction rate of formaldehyde was $22.28 \%$ and $23.45 \%$, respectively when reaction time was 180 min and $240 \mathrm{~min}$. Formaldehyde content was lowed by appropriately prolonging reaction time, and reduction rate of formaldehyde reached maximum value after $60 \mathrm{~min}$.

Optimization of reaction conditions by response surface methodology

Table 1 Design and results response surface experiment

\begin{tabular}{lllll}
\hline No & $\mathrm{pH}\left(\mathrm{X}_{1}\right)$ & $\begin{array}{l}\text { Temperature/ } \\
\left(\mathrm{X}_{2},{ }^{\circ} \mathrm{C}\right)\end{array}$ & Time/ $\left(\mathrm{X}_{3}, \mathrm{~min}\right)$ & $\begin{array}{l}\text { Reduction } \\
\text { rate/ } / \%)\end{array}$ \\
\hline 1 & 6 & 80 & 60 & 16.71 \\
2 & 8 & 80 & 60 & 35.93 \\
3 & 6 & 100 & 60 & 28.51 \\
4 & 8 & 100 & 60 & 47.05 \\
5 & 6 & 90 & 30 & 23.64 \\
6 & 8 & 90 & 30 & 33.95 \\
7 & 6 & 90 & 90 & 35.33 \\
8 & 8 & 90 & 90 & 65.99 \\
9 & 7 & 80 & 30 & 23.22 \\
10 & 7 & 100 & 30 & 28.88 \\
11 & 7 & 80 & 90 & 27.35 \\
12 & 7 & 100 & 90 & 56.60 \\
13 & 7 & 90 & 60 & 34.88 \\
14 & 7 & 90 & 60 & 32.32 \\
15 & 7 & 90 & 60 & 30.81 \\
16 & 7 & 90 & 60 & 34.82 \\
17 & 7 & 90 & 60 & 32.82 \\
\hline
\end{tabular}


Table 2 Variance analysis results

\begin{tabular}{lllllll}
\hline Parameter & $\begin{array}{l}\text { Degree of } \\
\text { freedom }\end{array}$ & $\begin{array}{l}\text { Sum of } \\
\text { squares }\end{array}$ & $\begin{array}{l}\text { Mean } \\
\text { square }\end{array}$ & F-value & P -value & Significant \\
\hline Model & 9 & 2292.99 & 254.78 & 36.43 & $<0.0001$ & $* * *$ \\
$\mathrm{X}_{1}$ & 1 & 774.80 & 774.80 & 110.79 & $<0.0001$ & $* * *$ \\
$\mathrm{X}_{2}$ & 1 & 418.04 & 418.04 & 59.78 & 0.0001 & $* * *$ \\
$\mathrm{X}_{3}$ & 1 & 714.04 & 714.04 & 102.10 & $<0.0001$ & $* * *$ \\
$\mathrm{X}_{1} \mathrm{X}_{2}$ & 1 & 0.12 & 0.12 & 0.017 & 0.9013 & $* *$ \\
$\mathrm{X}_{1} \mathrm{X}_{3}$ & 1 & 103.53 & 103.53 & 14.80 & 0.0063 & $* *$ \\
$\mathrm{X}_{2} \mathrm{X}_{3}$ & 1 & 139.12 & 139.12 & 19.89 & 0.0029 & $* .152$ \\
$\mathrm{X}_{1}^{2}$ & 1 & 22.61 & 22.61 & 3.23 & 0.1152 & $*$ \\
$\mathrm{X}_{2}^{2}$ & 1 & 48.60 & 48.60 & 6.95 & 0.0336 & $* *$ \\
$\mathrm{X}_{3}^{2}$ & 1 & 77.13 & 77.13 & 11.03 & 0.0127 & \\
Total error & 7 & 48.95 & 6.99 & & & \\
Lack of fit & 3 & 36.90 & 12.30 & 4.08 & 0.1039 & \\
Pure error & 4 & 12.05 & 3.01 & & & \\
Total SS & 16 & 2341.94 & & & & \\
& & $\mathrm{R}^{2}=0.97$ & & $\mathrm{R}_{\text {Adj }}^{2}=0.9522$ & & \\
& & 91 & & & \\
\hline
\end{tabular}

* Significant at 0.05 level, ** Significant at 0.01 level, *** Significant at 0.001 level

Response surface methodology was used to optimize the reaction conditions of polyphenols with formaldehyde. Experimental values obtained for reduction rate of formaldehyde (Y) at the designed points were shown in table 1 . After application of the response surface regression procedure, the predicted model can be described by the following equation:

$\mathrm{Y}=33.13+9.84 \mathrm{X}_{1}+7.23 \mathrm{X}_{2}+9.45 \mathrm{X}_{3}-0.17 \mathrm{X}_{1} \mathrm{X}_{2}+5.09 \mathrm{X}_{1} \mathrm{X}_{3}+5.90 \mathrm{X}_{2} \mathrm{X}_{3}+2.32 \mathrm{X}_{1}^{2}-3.40 \mathrm{X}_{2}^{2}+4.28 \mathrm{X}_{3}^{2}$.

On the basis of single factor experiment described above, the reaction conditions of blueberry leaf polyphenols with formaldehyde was optimized by response surface methodology. As shown in table 2 , we can find that the influence of reactivity of blueberry leaf polyphenols with formaldehyde decreased in the order $\mathrm{pH}\left(\mathrm{X}_{1}\right)>$ time $\left(\mathrm{X}_{3}\right)>$ temperature $\left(\mathrm{X}_{2}\right)$ according to the $\mathrm{F}$ value. According to the model (table2), linear terms of $\mathrm{pH}\left(\mathrm{X}_{1}, P<0.0001\right)$, temperature $\left(\mathrm{X}_{2}, P<0.0001\right)$, time $\left(\mathrm{X}_{3}\right.$, $P<0.0001)$, the quadratic terms of temperature $\left(\mathrm{X}_{2}^{2}, P<0.05\right)$ and time $\left(\mathrm{X}_{3}^{2}, P<0.01\right)$ reached statistical significance. The interaction of $\mathrm{pH}$ and time $\left(\mathrm{X}_{1} \mathrm{X}_{3}, P<0.01\right)$, and temperature and time $\left(\mathrm{X}_{2} \mathrm{X}_{3}, P<0.01\right)$ also reached statistical significance. The resulted showed that the change in the above three factors had a significant effect on the reaction capacity for polyphenols with formaldehyde. In contrast, the interaction between the $\mathrm{pH}$ and temperature $\left(\mathrm{X}_{1} \mathrm{X}_{2}\right)$ was not statistically significant $(P>0.05)$. Meanwhile, the whole model, including the linear level $(P<0.001)$, quadratic level $(P<0.05)$, and cross-product level $(P<0.01)$, all reached statistical significant $(P<0.05)$, while the lack of fit was not significant, indicating excellent agreement of the experiment values with the predicted values.

\section{Analysis of Box-Behnken experiment}

When one factor was fixed as the optical value calculated from the Box-Behnken experiment, the interaction of two elements on the reactivity of polyphenols with formaldehyde were shown in Fig.5 Fig.7. The effects of $\mathrm{pH}\left(\mathrm{X}_{1}\right)$ and temperature $\left(\mathrm{X}_{2}\right)$ on the reaction capacity are reflected in Fig.5. The effects of $\mathrm{pH}\left(\mathrm{X}_{1}\right)$ and temperature $\left(\mathrm{X}_{2}\right)$ were very significant $(P<0.001)$, but contour of $\mathrm{pH}$ is intensive, indicating $\mathrm{pH}$ is more significant than temperature for reduction rate of formaldehyde. The relationship between $\mathrm{pH}$ and time was illustrated in Fig.6, the factor $\mathrm{pH}\left(\mathrm{X}_{1}\right)$ is as significant as time $\left(X_{3}\right)$ in relation to the reaction capacity. The effects of temperature $\left(X_{2}\right)$ and time $\left(X_{3}\right)$ on the reaction capacity are shown in Fig.7, reaction time was more significant when compared with temperature. The best combination of process variables were $\mathrm{pH}$ of 8.0 , temperature of $100{ }^{\circ} \mathrm{C}$ and time of $88 \mathrm{~min}$. The responses calculated from the final polynomial functions were $68.87 \%$ of reduction rate of formaldehyde. 


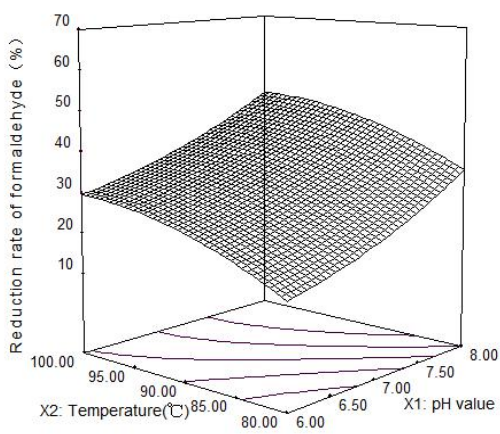

Fig. 5 Interactive effect of $\mathrm{pH}$ and temperature on reduction rate of formaldehyde

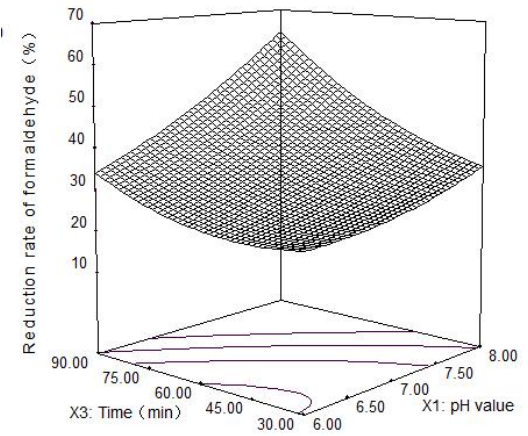

Fig.6 Interactive effect of $\mathrm{pH}$ and time on reduction rate of formaldehyde

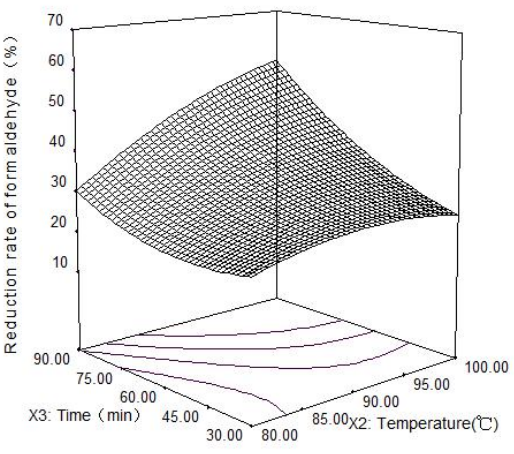

Fig. 7 Interactive effect of time and temperature on reduction rate of formaldehyde

\section{Conclusions}

The optimal polyphenols concentration was $0.2 \%$. The reaction activity was the lowest at $\mathrm{pH} 3.0-4.0$ and higher at strong acidic and alkaline conditions. Prolonging time facilitated the reaction under the higher temperature. The three variables could be ranked as follows in terms of the influence on the reaction performance: $\mathrm{pH}>$ time $>$ temperature. The best combination of process variables for the best set of response properties included $\mathrm{pH} 8.0$, temperature of $100{ }^{\circ} \mathrm{C}$ and time of $88 \mathrm{~min}$. Reduction rate of formaldehyde were $68.87 \%$ by calculated from the final polynomial functions. There is a great prospect with blueberry leaf polyphneols as formaldehyde capture agent for foods.

\section{Acknowledgements}

This work was supported by the National Natural Science Foundation of China (31201308).

\section{References}

[1] J.K Lin and D.C.Hurng: Fd Chem Toxzc. Vol. 23(1985), p.579.

[2] Z.Q.Tong, C.S.Han, M. Qiang, W.S.Wang, J.H.Lv, S. Z. Zhang, W. H. Luo, H. Li, H. J. Luo, J.N. Zhou, B.B.Wu, T. Su, X.Yang, X. M.Wang, Y. Liu and R.Q. He: Neurobiology of Aging. Vol. 36 No.1 (2015), p.100-110.

[3] P. Cole and C. Axten: Regul Toxicol Pharmacolol. Vol.40 No.2 (2004), p.107-112.

[4] X.Tang, Y. Bai, A.Duong, M.T.Smith, L. Li and L. Zhang: Environ Int. Vol. 35 No.8 (2009), p.1210-1224.

[5] Z.Lin, W. Luo, H. Li, Y.Zhang: Toxicol Lett.Vol.159 No.2 (2005), p. 134-143.

[6] K. Leelapongwattana, S. Benjakul, W.Visessanguan and N.K.Howell: Int. J. Food Sci. Technol. Vol.43(2008), 448-455.

[7] J.M. Garro Galvez, M. Fechtal and B. Riedl: Thermochimica Acta.Vol. 274(1996), p.149-163.

[8] J.L.Zhu, J.R.Li, L.L. Miao and X.P. Li: Journal of fisheries of China. Vol. 34(2010), p.375-381.

[9] V.L. Singleton, R.Orthofer and R.M. Lamuela-Raventos: Methods Enzymol. Vol.299, p.152-178 (1999).

[10] J.R.Li, J.L.Zhu and L.F.Ye: Asia Pac J Clin Nutr, Vol.16 (2007), p.127-130.

[11] J.L.Zhu, J.R.Li and J. Jia: J Sci Food Agric. Vol. 92(2012), p. 2436-2442. 